\title{
Rancang Bangun Aplikasi Pembayaran Kredit Sepeda Motor Pada Dealer Sepeda Motor Prima Service Menggununakan Bahasa Pemrograman Visual Basic.Net 2010
}

\author{
Reagan Surbakti Saragih ${ }^{1}$ \\ ${ }^{1}$ AMIK Parbina Nusantara Pematangsiantar, Indonesia
}

\section{Info Artikel \\ Article history: \\ Received: 21052019 \\ Revised: 23062019 \\ Accepted: 28072019 \\ Kata Kunci: \\ Aplikasi Pembayaran, Kredit Sepeda Motor, Dealer Sepeda Motor}

Penulis Korespondensi: agansaragih@gmail.com

\begin{abstract}
At this time the process of recording inventory data pata Toko Prima Service is still done manually, especially in terms of recording data on entry and exit of goods and making reports. With such a system causes frequent errors that can have an impact on overall installment payments. With the construction of this application will help the process of managing installment data to be more efficient. In building applications use Visual Basic.Net 2010. If this application is used then it is expected to make it easier to provide information to the leadership and the resulting report is effective data.
\end{abstract}

\begin{abstract}
Abstrak
Pada saat ini proses pencatatan data persediaan barang pata Toko Prima Service masih dilakukan secara manual, terutama dalam hal pencatatan data masuk dan keluarnya barang serta pembuatan laporan-laporan. Dengan sistem seperti itu menyebabkan sering terjadinya kesalahan yang dapat berdampak pada Pembayaran angsuran secara keseluruhan. Dengan dibangunnya aplikasi ini akan membantu proses pengelolaan data angsuran agar lebih efisien. Dalam membangun aplikasi menggunakan Visual Basic.Net 2010. Apabila aplikasi ini digunakan maka diharapkan dapat mempermudah memberikan informasi kepada pimpinan dan laporan yang dihasilkan merupakan data yang efektif.
\end{abstract}

\section{PENDAHULUAN}

Menurut jurnal [1] Perkembangan teknologi Informasi dan komunikasi sampai saat ini sangatlah pesat, seiring dengan perkembangan tersebut teknologi komputer merupakan salah satu alat yang sampai saat ini terus berkembang terutama di dunia usaha. Sampai sekarang teknologi komputer terus di pakai dan di manfaatkan oleh manusia dalam melakukan pekerjaan serta meningkatkan profesionalitas dalam bekerja dan mutu pelayanan dengan baik. Dalam perusahaan ini, penulis menemukan beberapa permintaan dari perusahaan terkait sistem yang di inginkan oleh pihak perusahaan, karena sistem yang mereka gunakan selama ini termasuk sistem yang sangat sederhana, karena sistem yang digunakan oleh perusahaan masih menggunakan sistem aplikasi Microsoft Excell sebagai penginputan data untuk mendata beberapa nasabah yang akan melakukan pembayaran kredit sepeda motor, berkaitan dengan sistem tersebut, perusahaan mengharapkan agar sistem dapat diganti untuk memiliki sistem yang lebih efisien lagi, agar dalam melakukan input data tersebut sangat mudah cepat dan aman.

\section{LANDASAN TEORI}

\subsection{Pengertian Rancang Bangun}

Menurut jurnal [3] Rancang bangun Merupakan salah satu hal yang penting dalam membuat program.Adapau tujuan dari perancangan adalah untuk memberikan bentuk dan desain yang jelas guna memudahkan pemrogram dalam membuat sebuah aplikasi.Perancangan harus mudah di pahami dan mudah di gunakan sehingga para pelaku program bisa menggunakan dan menerapkannya dengan baik dan benar.Perancangan merupakan serangkain prosedur untuk menterjemahkan hasil analisa ke dalam sebuah sistem dengan menggunakan bahasa pemrograman untuk menciptakan sebuah aplikasi yang dapat memudahkan dalam bekerja serta memperbaiki sistem yang sudah ada. 
Menurut jurnal [4] pengertian Rancang bangun adalah proses pembangunan sebuah sistem untuk menciptakan sebuah sistem baru maupun mengganti atau memperbaiki sistem yang telah ada baik secara keseluruhan maupun hanya sebagian, aplikasi yang di bangun harus sesuai dengan permintaan dan kebutuhan yang ada di setiap perusahaan yang nantinya bisa bekerja dan membantu dalam proses pengolahan data serta memberikan kemudahan dan kecepatan dalam proses transaksi pembayaran.

\subsection{Data}

Menurut Gordor B. Davis (1985). Data berasal dari bahasa latin yaitu "datum”, yang berarti fakta, kenyataan, kejadian, atau peristiwa. Jadi data adalah fakta dasar yang mewakili suatu kejadian. Data di proses oleh sistem komputer untuk menghasilkan informasi.[5] Menurut Al Bahra bin Ladjamudin (2005), Data dapat berupa angka dalam berbagai bentuk. Menurut Teguh Wahyono, (Sistem Informasi Konsep Dasar, Analisis Desain dan Implementasi), 2004; 2-3).[6]

\subsection{Defenisi Kredit}

Menurut jurnal [6] Pembayaran merupakan salah satu kegiatan atau usaha untuk membantu, melayani dan mengarahkan dan mengatur semua kegiatan di dalam mencapai suatu tujuan, karena pembayaran merupakan unsur penting bagi sebuah perusahaan maka di perlukan sebuah aplikasi yang bisa mengolah data pembayaran dengan sistem yang sudah terkomputerisasi dengan baik.

\subsection{Defenisi Sepeda Motor}

Menurut jurnal [8] Sepeda motor adalah salah satu kendaraan beroda dua yang di tenagai oleh sebuah mesin.Terdapat dua roda sepede motor yang sebaris yang berkecepatan tinggi dan sepda motor tetap tidak terbalik dan stabil karena di sebabkan adanya gaya giroskopik. Pada kecepatan rendah pengaturan berkelanjutan setangnya oleh pengendara yang memberikan kestabilan.

\subsection{Vsual Basic.Net}

Microsoft Visual Studio 2008 atau Visual Basic.Net merupakan aplikasi pemrograman yang menggunakan teknologi .Net Framework. Teknologi .Net Framework merupakan komponen windows yang terintegrasi serta mendukung pembuatan, penggunaan aplikasi, dan halaman web. Menurut Budiarto (2002:95), [9]Visual Basic adalah salah satu bahasa pemrograman komputer yang digunakan untuk aplikasi windows yang berbasis GUI (Graphical User Interface). Visual Basic merupakan event-driven programming (Pemrograman terkendali kejadian) artinya program menunggu sampai adanya respon dari pemakai berupa kejadian tertentu (tombol di klik, menu dipilih, dan lain-lain).[10]

\subsection{Microsoft Access}

Menurut Taufani (2009:1) Microsoft Access 2007 atau lebih dikenal dengan sebutan Access 2007 merupakan salah satu aplikasi yang diperuntukkan untuk mengolah database di bawah sistem Windows. Aplikasi yang merupakan salah satu aplikasi berbasis data relasional bagian dari Microsoft Office ini ditujukan kepada kalangan perusahaan kecil hingga perusahaan menengah yang dikhususkan untuk perancangan dan pengolahan berbagai macam database.[11] yang menyediakan fasilitas seperti tabel sebagai objek utama dalam database yang digunakan untuk menyimpan sekumpulan data sejenis dalam sebuah objek, query yang merupakan suatu bahasa untuk melakukan manipulasi terhadap database yang digunakan untuk menampilkan, mengubah dan menganalisis sekumpulan data, form digunakan untuk mengontrol proses masukan data (input), menampilkan data (output), memeriksa dan memperbaharui data dan report yang berfungsi untuk menampilkan data yang sudah dirangkum dan mencetak data yang di input.[12]

\section{ANALISA DAN PERANCANGAN}

\subsection{Analisa}

Dalam melaksanakan penelitian penulis melakukan analisa masalah pada pembayaran kredit sepeda motor pada Dealer sepeda motor Prima Service dimana di setiap proses pengolahan datanya masih menggunakan Microsoft Office Exel sehingga data yang di masukan belum otomastis secara terkomputerisasi dengan baik ,tentu ini menjadi masalah bagi perusahaan terutama bagi masyarakat dimana mereka akan menunggu terlalu lama ketika proses transaksi berjalan dengan lambat, hal ini menyebabkan tidak efektifnya pekerjaan dan mempengaruhi kualitas perusahaan di mata konsumen.Sehingga konsumen banyak mengeluh dan protes. Seperti gambar di bawah ini merupakan system jalanya transaksi pembayaran kredit sepeda motor pada Dealer sepeda motor prima service Rantauprapat. 


\subsection{Perancangan}

Perancangan merupakan proses dimana kita akan merancang dan melakukan penggambaran sebuah system yang akan di bangun sebelum pembuatan system di lakukan, pada tahap ini penulis akan merancang sebuah system yang nantinya bisa bekerja denga baik dengan menggunakan pemodelan UML (Unified Modelling Languge).

\subsubsection{Usecase Diagram}

Dalam menyusun alur usecase di perlukan sebuah alur untuk menjalankan sebuah system, dimana alur yang di susun nantinya akan merepresentasikan sebuah interaksi antara aktor dengan system. Seorang aktor adalah sebuah entias manusia atau mesin yang berinteraksi dengan system untuk melakukan pekerjaan - pekerjaan tertentu. Berikut adalah gambaran dan aktivitas yang terjadi di dalam usecase diagram yang telah panulis rancang4.

\section{IMPLEMENTASI}

\subsection{Kebutuhan Sistem}

Implementasi merupakan tahap dari aplikasi yang sudah dibangun dan dirancang. Selanjutnya dilakukan uji kelayakan terhadap aplikasi sehingga user dapat memberikan masukan demi berkembangnya aplikasi yang telah dibangun.[9] Adapun aplikasi yang telah dibangun adalah aplikasi data gudang sparepart. Selain itu, dibutuhkan perangkat keras dan perangkat lunak yang digunakan untuk melakukan implementasi dan pengujian terhadap aplikasi [12] yaitu sebagai berikut:

1. Perangkat keras (Hardware) yang digunakan untuk analisis dan perancangan sistem adalah :
a. Processor Intel core $2 \mathrm{dUO}$
b. Monitor Lcd $14 \mathrm{Inc}$
c. VGA Card $512 \mathrm{mb}$
d. RAM 4 GB
e. Keyboard
f. Mouse
g. Harddisk $320 \mathrm{gb}$

2. Perangkat lunak (Software) yang digunakan untuk analisis dan perancangan sistem :
a. Windows 7
b. Microsoft Visual Studio 2010
c. Micorosoft Access 2010

\subsection{Tampilan Program}

1. Tampilan form login

Login merupakan sebuah proses untuk mengakses sebuah computer dengan memasukkan sebuah identitas diri dengan bentuk sebuah akun pengguna dan sebuah kata sandi, dan kata sandi sebagai salah satu bentuk keamanan yang ada pada sebuah aplikasi.Bentuk desain dari sebuah tampilan login adalah sebagai berikut.

\section{Gambar 4.1 Tampilan Form}

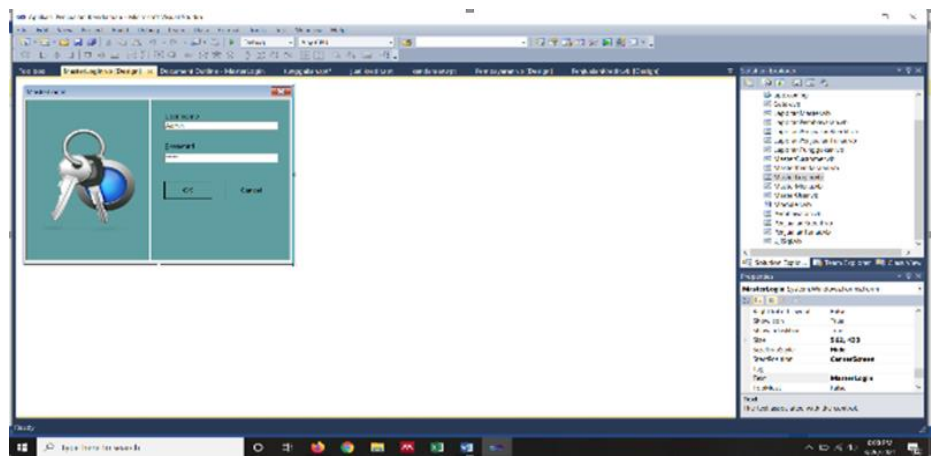




\section{Tampilan Form Menu Utama}

Tampilan menu utama merupakan sebuah tampilan yang akan menampilkan menu - menu yang akan di lakukan untuk memasukkan atau menginput data ke dalam sebuah aplikasi yang akan di simpan ke dalam sebuah database bentuk dan tampilan dari menu utama

\section{Gambar 4.2 Tampilan Form Menu Utama}

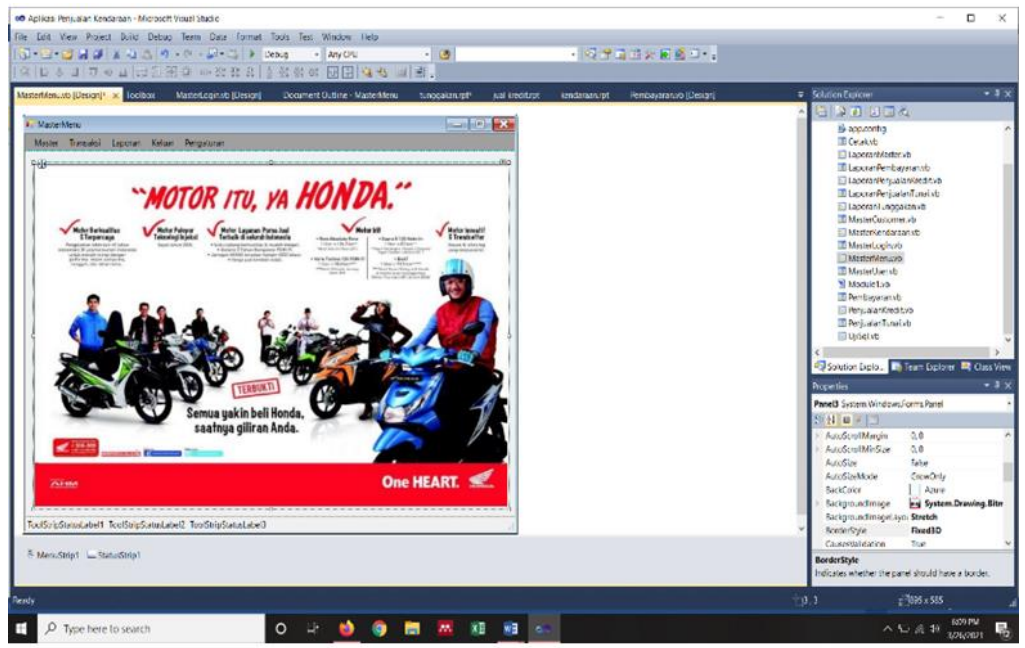

\section{Tampilan data customer}

Tamilan data customer merupakan sebuah tampilan yang di gunakan untuk menginput data pelanggan atau customer selaku nasabah yang melakukan pembelian sepeda motor secara tunai dan kredit, serta pelanggan setia Dealer sepeda motor prima service Rantauprapat.dengan adanya menu data customer admin akan lebih mudah dalam melakukan penginputan data tanpa harus repot - repot mencatatnya dengan kertas atau pun buku tulis. Bentuk tampilan dan designya adalah sebagai berikut

\section{Gambar 4.3 Tamilan data customer}

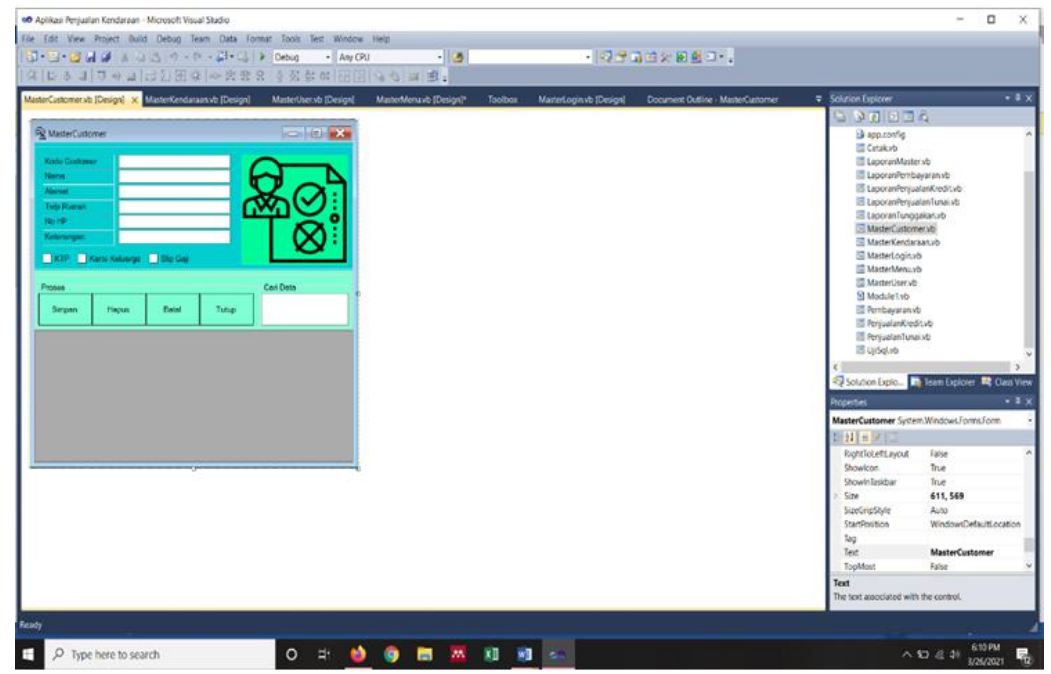

\section{Tampilan penjualan tunai}

Tampilan penjualan tunai merupakan sebuah tampilan menu dimana pada menu ini berupa tampilan yang memiliki karakter seperti nmor, tanggal, kode, merk, jenis, Tahun, isi silinder, No.Rangka, No.Mesin, warna, Bahan bakar, Harga Cash, Kode customer, nama dan alamat, di dalam menu ini admin akan melakukan penginputan data ke aplikasi dimana aplikasi akan bekerja sesuai perintah yang telah di lakukan, dalam menu ini aplikasi akan menyimpan data penjualan tunai yaiu data nasabah yang melakukan pembelikan kredit sepeda motor secara tunai.Bentuk tampilan dan design dari tampilan penjualan tunai adalah sebagai berikut : 


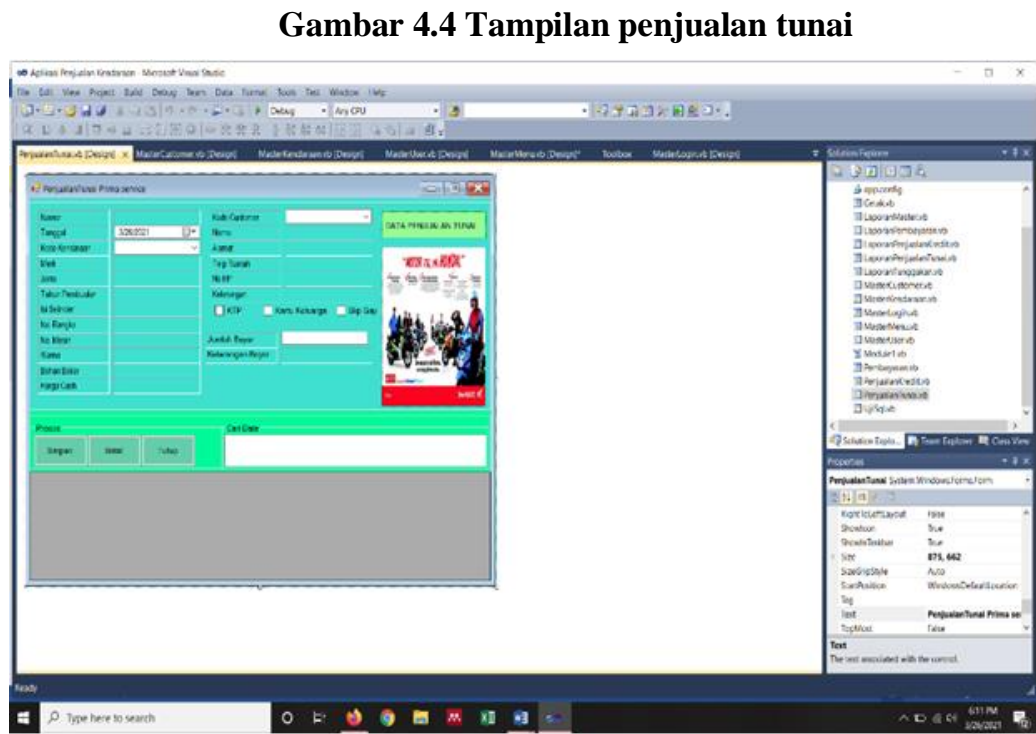

\section{Tampilan Form Transaksi Penjualan}

Di dalam tampilan kredit beriti tentang data nasabah yang melakukan pembelian sepeda motor secara kredit dengan melakukan pembayaran uang muka terlebih dahulu,bentuk tampilan data penjualan kredit adalah sebagai berikut :

\section{Gambar 4.5 Tampilan Form Transaksi Penjualan}

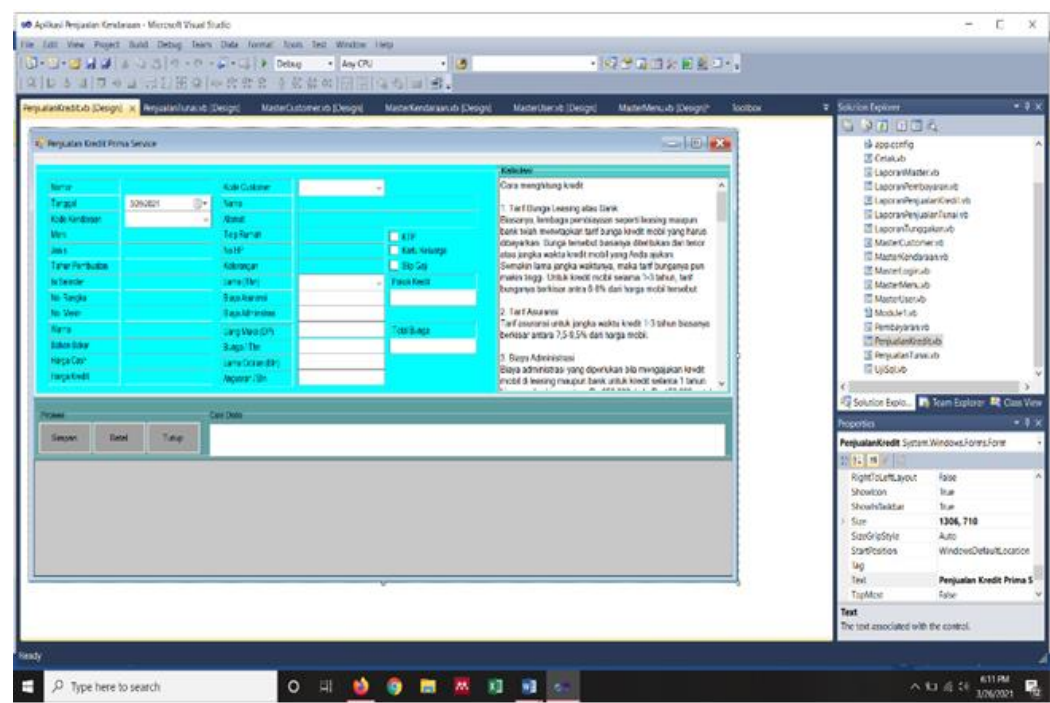

\section{Tampilan Pembayaran Kredit}

Pada tampilan pembayaran kredit aplikasi akan menampilan data nasabah yang melakukan pembayaran angsuran per setiap bulanya yang sudah di tetapkan oleh peraturan dan kesepakatan, di dalam menu pembayaran kredit aplikasi nantinya akan menyimpan seluruh data nama nasabah yang sudah membayar angsuran dan akan di laporkan per setiap bulanya ke pimpinan perusahaan. Bentuk tampilan dan design dari menu pembayaran kredit adalah sebagai berikut 


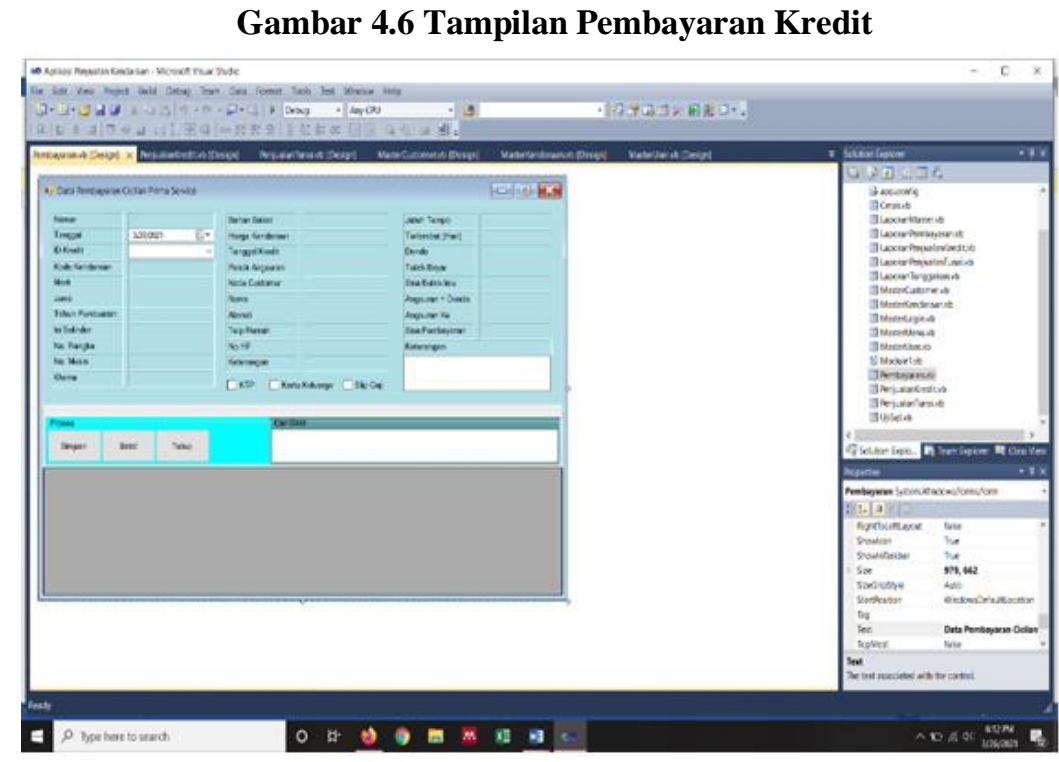

\section{Tampilan Laporan Data Custome}

Pada tampilan laporan data customer terdapat beberapa karakter yang akan di gunakan dalam membuat laporan data customer,pada laporan ini akan melaporkan nama - nama nasabah yang telah melakukan pembelian kredit sepeda motor dan juga pelanggan tetap,berikut tampilan laporan data customer

\section{Gambar 4.7 Tampilan Laporan Data Custome}

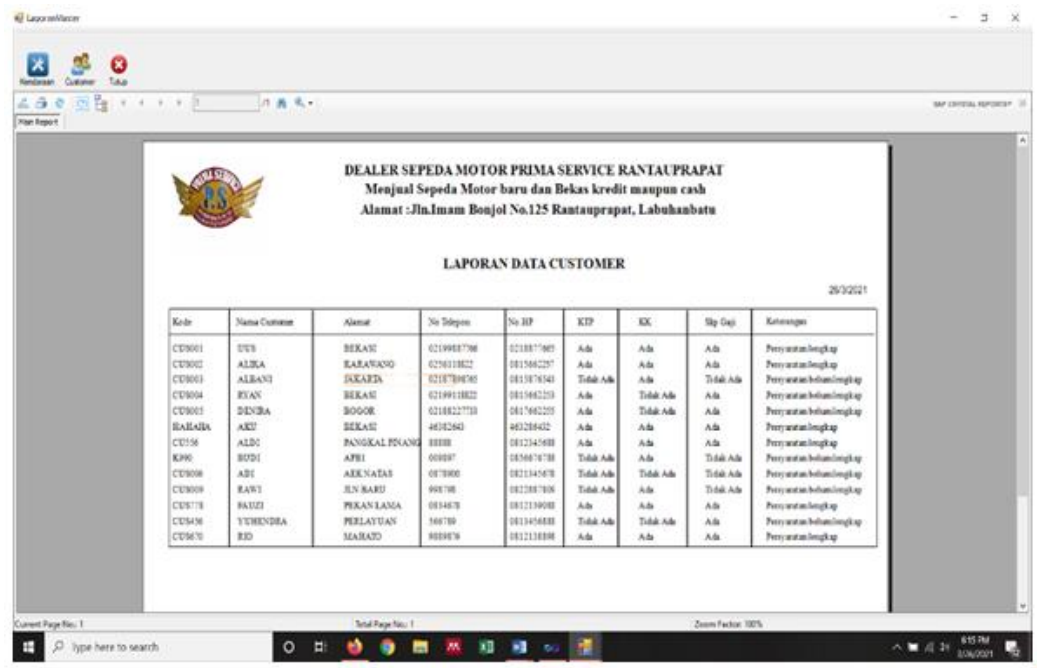

\section{Tampilan Form Laporan Data Kendaraan}

Pada laporan data kendaraan terdapat data kendaraan yang akan di jual yang sesuai dengan bentuk dan harganya masing - masing, maka dari itu semua data kendaraan akan didata dan di inputkan ke dalam aplikasi pembayaran kredit sepeda motor, sehingga data kendaraan akan aman dan akan di simpan ke dalam sebuah database dan tidak akan takut tercecer ataupun hilang,berikut bentuk tampilan laporan data kendaraan 


\section{Gambar 4.7 Tampilan Form Laporan Data Kendaraan}

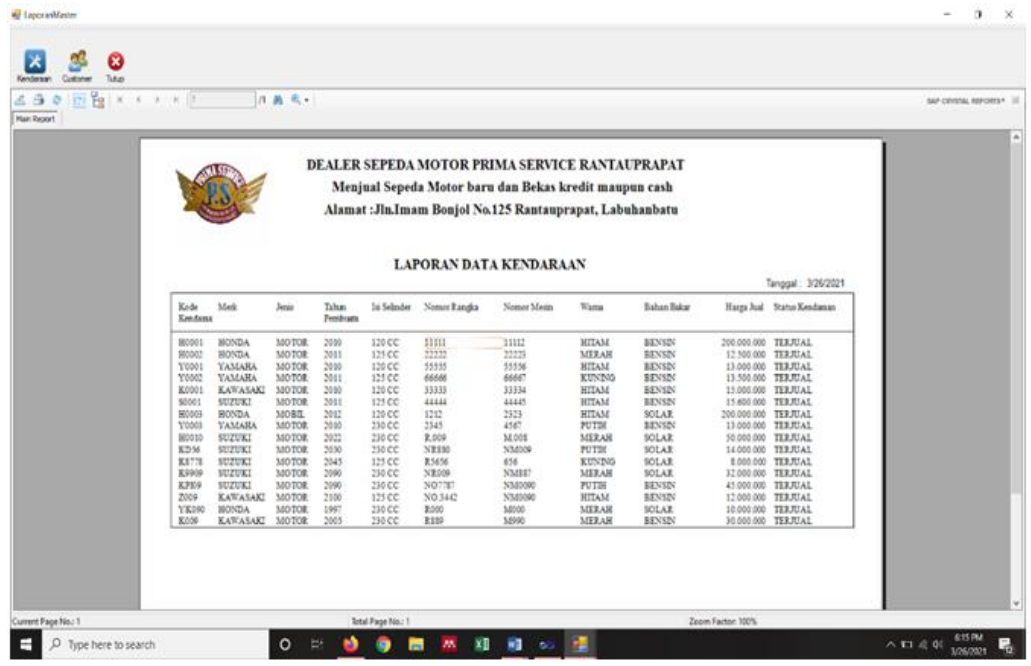

\section{KESIMPULAN DAN SARAN}

\subsection{Kesimpulan}

Berdasarkan pembahasan program secara keseluruhan, maka kesimpulan yang di dapat oleh penulis adalah sebagai berikut:

1. Peranan computer sangatlah penting bagi kemajuan usaha di bidang penjualan, terutama di dunia usaha maka dari itu dalam melakukan kegiatan pengolahan data dan pembuatan laporan. Dalam hal ini computer dapat mempermudah setiap aktivitas dan kegiatan manusia.

2. Pengolahan data pada aplikasi pembayaran kredit sepeda motor dengan sebuah aplikasi yang sudah di rancang dapat mempermudah pekerjaan yang nantinya akan di lakukan, sehingga pekerjaan yang di kerjakan akan lebih cepat selesai, efisien dan akurat.

\subsection{Saran}

1. Mendukung sebuah transaksi pengolahan data yaitu pada proses penjualan dan pembelian yang berlangsung dengan baik, dengan

2. pengolahan data yang cepat dan simple maka keuntungan yang di dapat akan jauh lebih besar,

3. perkembangan perangkat lunak saat ini sudah semakin maju, oleh karena itu di butuhkan pula tenaga yang handal dalam membuat sebuah program yang bagus dan terampil, sehingga aplikasi ini akan terus berkembang dan mampu bersaing di dunia luar

4. di dalam dunia usaha haruslah bisa bersaing dan berani mengambil resiko maka dari itu setiap pekerjaan yang di lakukan haruslah di kerjakan dengan baik dan benar guna mencapai hasil yang memuaskan. Dengan aplikasi yang sudah di buat penulis maka penulis berharap aplikasi ini bisa berguna buat masyrakat luas terutama di perusahaan - perusahaan ternama 


\section{REFERENSI}

[1] W. Fahrozi, P. T. Informatika, T. Informatika, F. U. A. Labuhanbatu, T. Mulia, and K. Medan, "UNET : Jurnal Teknik Informatika LPPM - Universitas Al Washliyah Labuhanbatu 23 | P a g e UNET : Jurnal Teknik Informatika Sebagai langkah awal yang dilakukan supaya dapat mengetahui gambaran permasalahan yang dihadapi dalam menentukan rasa yam serama a," vol. 3, no. 5, pp. 2327, 2019.

[2] M. V. B. Net, "PADA TOKO URIP MOTOR," no. September, pp. 1-6, 2020.

[3] Samsir, D. I. G. Hts, and S. Z. Harahap, "SPK Untuk Pemilihan Kepala Sekolah Menggunakan Metode Saw dan Profile Matching," U-NET J. Tek. Inform., 2020.

[4] J. H. P. Sitorus et al., "Perancangan pengontrol lampu rumah miniatur dengan menggunakan micro controler arduino berbasis android 1," vol. 4, no. 1, pp. 1-11, 2020.

[5] U. Verawardina, F. Edi, and R. Watrianthos, "Analisis Sentimen Pembelajaran Daring Pada Twitter di Masa Pandemi COVID-19 Menggunakan Metode Naïve Bayes," vol. 5, pp. 157-163, 2021, doi: 10.30865/mib.v5i1.2604.

[6] S. Zulkifli, "Implementasi Sistem Keamanan SQL Injection Dalam berbasis web," Ejurnal.Univalabuhanbatu.Ac.Id, vol. 04, no. 01, pp. 13-17, 2020, [Online]. Available: https://ejurnal.univalabuhanbatu.ac.id/index.php/u-net/article/download/164/130.

[7] Syaiful Zuhri Harahap and Samsir, "Application Design The Data Collection Features of The Hotel Shades of Rantauprapat Using VBNET," Int. J. Sci. Technol. Manag., 2020, doi: 10.46729/ijstm.v1i1.4.

[8] Samsir and Syaiful Zuhri Harahap, “Application Design Resume Medical By Using Microsoft Visual Basic. Net 2010 At the Health Center Appointments," Int. J. Sci. Technol. Manag., vol. 1, no. 1, pp. 14-20, 2020, doi: 10.46729/ijstm.v1i1.5.

[9] M. Siddik and S. Samsir, "Rancang Bangun Sistem Informasi Pos (Point of Sale) Untuk Kasir Menggunakan Konsep Bahasa Pemrograman Orientasi Objek," JOISIE (Journal Inf. Syst. Informatics Eng., vol. 4, no. 1, p. 43, 2020, doi: 10.35145/joisie.v4i1.607.

[10] P. T. Informatika and F. U. A. Labuhanbatu, "U-NET: Jurnal Teknik Informatika LPPM Universitas Al Washliyah Labuhanbatu 18 | P a g e U-NET: Jurnal Teknik Informatika Sebagai langkah awal yang dilakukan supaya dapat mengetahui gambaran permasalahan yang dihadapi oleh bagian kesiswaan adalah denga," vol. 3, no. 4, pp. 18-22, 2019.

[11] D. Indra et al., "SPK Untuk Pemilihan Kepala Sekolah Menggunakan Metode Saw dan Profile Matching," vol. 4, no. 1, pp. 7-12, 2020.

[12] Samsir, "Klasifikasi Penyakit Tenggorokan Hidung Telinga ( THT ) Menggunakan Jaringan Syaraf Tiruan Dengan Metode Learning Vektor Quantization ( THT ) Di RSUD Rantauprapat Labuhanbatu Klasifikasi penyakit Tenggorokan Hidung Telinga ( THT ) Menggunakan,” vol. 05, no. 01, pp. 3847, 2019.

[13] R. A. Purba, S. Samsir, M. Siddik, S. Sondang, and M. F. Nasir, "The optimalization of backpropagation neural networks to simplify decision making," IOP Conf. Ser. Mater. Sci. Eng., vol. 830, no. 2, 2020, doi: 10.1088/1757-899X/830/2/022091.

[14] S. Samsir, S. Suparno, and M. Giatman, "Predicting the loan risk towards new customer applying data mining using nearest neighbor algorithm," IOP Conf. Ser. Mater. Sci. Eng., vol. 830, no. 3, 2020, doi: 10.1088/1757-899X/830/3/032004.

[15] D. I. G. H. Wirhan Fahrozi, Samsir, "Penerapan E-Commerce Pada Toko Bunga Underwear," J. Tek. Inform., vol. 04, no. 01, pp. 1-6, 2020.

[16] F. Edi, P. T. Informatika, and F. U. A. Labuhanbatu, "UNET | Jurnal Ilmiah Teknik Informatika LPPM Universitas Al Washliyah Labuhanbatu UNET | Jurnal Ilmiah Teknik Informatika ISSN . 2460-3694, Vol . 2 No . 1 Februari 2018," vol. 2, no. 1, pp. 2-5, 2018. 